\title{
Current Response of lonophore-Based Ion-Selective Electrode Membranes at Controlled Potential
}

\author{
Werner E. Morfa, Titus Zwickl ${ }^{b}$, Ernö Pretsch, ${ }^{\mathrm{b} *}$ and Nico F. de Rooija*
}

\begin{abstract}
From electrochemical measurements at the interface of two immiscible electrolytes, the current at controlled potential is usually a linear function of the ion concentration in the aqueous phase. Surprisingly, a linear relationship between the current and the logarithm of the sample ion activity is found here for corresponding measurements on ion-selective electrode membranes. Here we document these new findings and give a theoretical explanation for the apparent contradiction between the results obtained with the two kinds of systems.
\end{abstract}

Keywords: Current response $\cdot$ Ion-selective electrodes $\cdot$ Theory

\section{Introduction}

Ion-selective electrodes (ISEs) based on ionophore membranes continue to be a focus of interest in analytical chemistry. Besides highly relevant applications of potentiometric sensors, a series of more fundamental aspects have been addressed in recent papers on this subject (for a review see [1]). The aim of different investigations was to improve the lower detection limit and the selectivity behavior of commonly applied ISE types [2][3]. Spectacular effects have been achieved by optimizing the inner solution and the membrane composition [4-6]. Additionally, it has been shown that the modulation of the potentiometric response by a controlled transmembrane

\footnotetext{
${ }^{*}$ Correspondence: Prof. N.F. de Rooij alnstitute of Microtechnology (IMT) University of Neuchâtel

Rue Jaquet-Droz 1

$\mathrm{CH}-2007$ Neuchâtel

Tel.: +4132720 5303

Fax: +4132720 5711

E-Mail: nico.derooij@imt.unine.ch

Prof. E. Pretsch

bLaboratorium für Organische Chemie

ETH Hönggerberg, $\mathrm{HCl} \mathrm{E} 313$

$\mathrm{CH}-8093$ Zürich

Tel.: +4116322926

Fax: +4116321164

E-Mail: pretsch@org.chem.ethz.ch
}

current can improve the response characteristics [7-9]. The insight gained from these studies led us to the design of new experiments on ionophore membranes [10-12]. Here, we report first results on the current response of ISE systems in measurements performed at constant potential.

In the past, the ionophore-mediated current flow through membranes has been investigated by several groups ([13-15] and references found therein). While earlier two-phase systems were preferably investigated (electrochemistry at the interface of two immiscible electrolytes, ITIES [13] [14][16]), three-phase systems consisting of a lipophilic and two aqueous phases became the focus of more recent studies [17-22]. Cyclic voltammetric investigations on such systems [17][18] were primarily of fundamental interest. However, pulsed amperometry with polymeric membranes turned out to be a promising new analytical method [19-22]. Chronoamperometry, on the other hand, seems to be especially useful for the diagnosis of the membrane [23][24].

Concerning the voltammetric or amperometric current response, the results presented so far were partly contradictory. For example, it was concluded from investigations of ion transfer across the interfaces (aqueous/organic phase) between immiscible electrolyte solutions that such systems may exhibit a voltammetric or amperometric current response that is directly propor- tional to the concentration of the ions involved [25][26]. This is definitely at variance with results obtained from bipolar pulse conductance measurements on ionophore membranes where the current signals apparently turned out to be proportional to the logarithm of ion concentration or activity [27].

The present contribution offers an explanation for the conflicting current-response behavior found for ISE membranes and related model systems.

\section{Theoretical Section}

The electrical characteristics of ionophore-based ISEs have been successfully interpreted by treating the membrane as an electroneutral phase that contains a given amount of nearly immobile anions [6] [15][28]. These 'fixed' anionic sites ensure, together with the ionophores as cation-specific complexing agents, a highly selective transfer of the primary cations $\mathrm{M}^{\mathrm{Z}_{\mathrm{m}}}$ into and through the membrane. Hence, the potentiometric response of such ideally performing ISEs follows the Nernst equation, Eqn. (1) [15][28]:

$$
\mathrm{E}(\mathrm{i}=0)=\mathrm{E}_{\mathrm{m}}^{\mathrm{o}}+\left(\mathrm{RT} / \mathrm{z}_{\mathrm{m}} \mathrm{F}\right) \ln \mathrm{a}_{\mathrm{m}}
$$

where $\mathrm{E}(\mathrm{i}=0)$ is the electrode potential at zero current (electromotive force), $\mathrm{E}_{\mathrm{m}}^{\mathrm{o}}$ is the reference potential of the ISE, including 
all contributions except for the membranesample interface, $\mathrm{RT} / \mathrm{z}_{\mathrm{m}} \mathrm{F}$ is the Nernstian factor $\left(25.69 \mathrm{mV} / \mathrm{z}_{\mathrm{m}}\right.$ at $\left.25^{\circ} \mathrm{C}\right)$, and $\mathrm{a}_{\mathrm{m}}$ is the nominal activity of primary ions in the sample solution.

When an electrical current flows through the ISE membrane, two major deviations from the above-described behavior occur. First, the current-induced flux of cations results in the generation of a diffusion layer between the bulk of sample solution and the ion-sensing membrane surface. Correspondingly, a difference between the nominal bulk activity $\mathrm{a}_{\mathrm{m}}$ and the actually sensed boundary activity a' ${ }_{m}$ arises. Secondly, an additional potential drop is generated within the membrane having an ohmic resistance $\mathrm{R}_{\mathrm{ISE}}$ :

$$
\mathrm{E}=\mathrm{E}_{\mathrm{m}}^{\mathrm{o}}+\left(\mathrm{RT} / \mathrm{z}_{\mathrm{m}} \mathrm{F}\right) \operatorname{lna}_{\mathrm{m}}-\mathrm{R}_{\mathrm{ISE}} \mathrm{i}
$$

where $\mathrm{E}$ is the electrode potential at a given current $\mathrm{i}$.

It should be noted that the current flow also causes two other effects, namely an ion activity gradient formed between the inner membrane surface and the internal solution of the ISE, and a concentration gradient of free ionophores built up within the membrane [29-32]. These phenomena can be minimized by an adequate choice of the experimental parameters [33] and are therefore neglected in the present work.

From Eqns. (1) and (2), the basic current-voltage relationship is given by:

$$
\mathrm{E}=\mathrm{E}(\mathrm{i}=0)+\left(\mathrm{RT} / \mathrm{z}_{\mathrm{m}} \mathrm{F}\right) \ln \left(\mathrm{a}^{\prime}{ }_{\mathrm{m}} / \mathrm{a}_{\mathrm{m}}\right)-\mathrm{R}_{\mathrm{ISE}} \mathrm{i}
$$

The activity ratio as a function of the current is obtained from an expression for the diffusion flux $\mathrm{J}_{\mathrm{m}}$ of primary ions in the sample boundary layer:

$$
\begin{aligned}
& \mathrm{i}=\mathrm{AFz}_{\mathrm{m}} \mathrm{J}_{\mathrm{m}}=\mathrm{AFz}_{\mathrm{m}} \mathrm{D}_{\mathrm{m}}\left(\mathrm{c}_{\mathrm{m}}-\mathrm{c}_{\mathrm{m}}^{\prime}\right) / \delta \\
& \mathrm{i}_{\lim }=\mathrm{AFz}_{\mathrm{m}} \mathrm{D}_{\mathrm{m}} \mathrm{c}_{\mathrm{m}} / \delta
\end{aligned}
$$

where $c_{m}$ and $c^{\prime}$ are the bulk value and the boundary value of sample ion concentration, respectively, $\mathrm{D}_{\mathrm{m}}$ is the ionic diffusion coefficient in aqueous solution, $\mathrm{A}$ is the cross section area and $\delta$ the thickness of the aqueous diffusion layer, $\mathrm{i}_{\lim }$ is the limiting current reached for $\mathrm{c}^{\prime}{ }_{\mathrm{m}} \rightarrow 0$, and $\mathrm{F}$ is the Faraday equivalent. When the ratio $\mathrm{c}^{\prime} \mathrm{m}_{\mathrm{m}} / \mathrm{c}_{\mathrm{m}}$ is determined from Eqns. (4) and (5) and substituted for the activity ratio in Eqn. (3), the final result reads as:
The second term is basically the description of voltammetric or amperometric ion transfer across the interface between two immiscible electrolyte systems [13] [14][16], and the third term accounts for the current-induced ion transport through the interior of the membrane phase [29][31] [32].

\section{Experimental Section}

\subsection{Reagents}

Poly(vinyl chloride) (PVC), bis(2-ethylhexyl) sebacate (DOS), potassium tetrakis ( $p$-chlorophenyl) borate (KTpClPB), the ionophore $\mathrm{N}, \mathrm{N}$-dicyclohexyl-N',N'-dioctadecyl-3-oxapentanediamide (ETH 5234), and tetrahydrofuran (THF) were from Fluka AG (CH-9470 Buchs, Switzerland). Aqueous solutions were prepared with freshly deionized water $(18.0 \mathrm{M} \Omega \mathrm{cm}$ specific resistance) obtained with a NANOpure $^{\mathrm{TM}}$ reagent-grade water system (Barnstead, CH-4009 Basel, Switzerland). Hydrochloric acid, $\mathrm{CaCl}_{2}$, and $\mathrm{KCl}$ were of Suprapur ${ }^{\circledR}$ quality from Merck (Darmstadt, Germany).

\subsection{Membranes}

Membranes contained 1.0 wt \% (12.7 mmol kg-1) ETH 5234, $0.3 \mathrm{wt} \%$ (5.4 mmol $\mathrm{kg}^{-1}$ ) KTpClPB, 65.9 wt \% DOS, and 32.8 wt \% PVC. Membranes of $c a .150 \mu \mathrm{m}$ thickness were obtained by casting a solution of ca. $240 \mathrm{mg}$ of the membrane components, dissolved in ca. $2.5 \mathrm{ml}$ of THF, into a glass ring ( $28 \mathrm{~mm}$ i.d.) fixed on a glass plate.

\subsection{Controlled-potential Current Measurements}

A custom-made plexiglass symmetrical cell with a volume of $3 \mathrm{ml}$ and an exposed membrane area of $1 \mathrm{~cm}^{2}$ was used. One of its compartments was connected to a reservoir containing $97 \mathrm{ml}$ of the sample and the solution of total $100 \mathrm{ml}$ was continuously pumped through the cell interior. The cell was equipped with working and counter electrodes $\mathrm{Ag} \mid \mathrm{AgCl}\left(1 \mathrm{~cm}^{2}\right)$ and two identical reference electrodes (Metrohm type 6.0729.100, $\mathrm{Ag} \mid \mathrm{AgCl}$ in $1 \mathrm{M} \mathrm{KCl})$ with a bridge electrolyte of $10^{-3} \mathrm{M} \mathrm{KCl}, 10^{-4} \mathrm{M}$ $\mathrm{HCl} ; \mathrm{pH}$ 3.8. The external potential difference was controlled with an SI 1287 Electrochemical Interface (Solartron Instruments, Farnborough, Hampshire, UK) using a custom-made program written in LabView 5.1 (National Instruments, Austin, TX). The same instrument was used to measure the current response $\left(20-21{ }^{\circ} \mathrm{C}\right)$. The membrane was initially conditioned for $2.5 \mathrm{~d}$, and between measurements for
$3.5 \mathrm{~h}$ with $10^{-3} \mathrm{M} \mathrm{CaCl}_{2}$ and a background electrolyte of $10^{-3} \mathrm{M} \mathrm{KCl}$ and $10^{-4} \mathrm{M} \mathrm{HCl}$ ( $\mathrm{pH}$ 3.8) in both compartments of the cell. Then, the calibration curves were taken at applied external potential differences of -30 and $-0.3 \mathrm{mV}$, respectively, by successive automatic dilution of the conditioning solution with the background electrolyte solution in one of the compartments with a Metrohm Liquino (Metrohm AG, CH-9010 Herisau, Switzerland). At each concentration, current readings were taken after 30 min.

\section{Results and Discussion}

The given relationships offer a straightforward description of the current response $i$ of ISE membranes in experiments performed at controlled potential (i.e. $\mathrm{E}=$ const). Two limiting cases can be discerned for the resulting current characteristics, depending on the actual parameters of the measuring system. If the absolute value of the applied potential is sufficiently low and the current signal is much lower than the limiting value, the following simple expression is obtained from Eqns. (6) and (1):

$$
\begin{gathered}
\mathrm{R}_{\mathrm{ISE}} \mathrm{i} \approx\left(\mathrm{E}_{\mathrm{m}}^{\mathrm{o}}-\mathrm{E}\right)+\left(\mathrm{RT} / \mathrm{z}_{\mathrm{m}} \mathrm{F}\right) \ln \mathrm{n}_{\mathrm{m}}= \\
\text { Const }+\left(\mathrm{RT} / \mathrm{z}_{\mathrm{m}} \mathrm{F}\right) \ln \mathrm{a}_{\mathrm{m}}
\end{gathered}
$$

It becomes evident that, in this case, the current response perfectly mimics the potentiometric response curve of the respective ISE at zero current. Hence, the current signal is here strictly related to the logarithm of ion activity (see also below). This is in striking contrast to the purely linear concentration-dependence expected from conventional amperometric or voltammetric experiments [16][25][26].

On the other hand, if the potential value is very high and the current approaches its limit, the description according to Eqns. (6) and (5) clearly reduces to:

$\mathrm{i} \approx\left(\mathrm{AFz}_{\mathrm{m}} \mathrm{D}_{\mathrm{m}} / \delta\right) \mathrm{c}_{\mathrm{m}}$

This case obviously agrees with the diffusion-limited current behavior encountered in classical amperometry or voltammetry. Since the resistances of the common polymer membranes used for ISEs are comparatively high, the basic condition $\mathrm{i} \rightarrow \mathrm{i}_{\text {lim }}$ can be fulfilled only if the potential is high enough and/or the sample concentration quite low. 
The current-voltage relationship in Eqn. (6) can also be rearranged to yield the expression:

$$
\begin{aligned}
& \mathrm{R}_{\mathrm{ISE}} \mathrm{i}=\left(\mathrm{E}_{\mathrm{m}}^{\mathrm{o}}-\mathrm{E}\right)+\left(\mathrm{RT} / \mathrm{z}_{\mathrm{m}} \mathrm{F}\right) \ln \left(\mathrm{a}_{\mathrm{m}}+\Delta \mathrm{a}_{\mathrm{m}, \mathrm{el}}\right) \\
& \Delta \mathrm{a}_{\mathrm{m}, \mathrm{el}}=-\left(\mathrm{a}_{\mathrm{m}} / \mathrm{i}_{\mathrm{lim}}\right) \mathrm{i}=-\left(\delta \gamma_{\mathrm{m}} / \mathrm{AFz}_{\mathrm{m}} \mathrm{D}_{\mathrm{m}}\right) \mathrm{i}
\end{aligned}
$$

where $\Delta \mathrm{a}_{\mathrm{m}, \mathrm{el}}$ constitutes a contribution to the detection limit of the ISE system [9]. This activity increment obviously depends on the current, but is independent of all membrane parameters except for the area $\mathrm{A}$ $\left(\gamma_{\mathrm{m}}\right.$ is the ion activity coefficient in the sample). The result illustrates that the analytically useful activity range of an ISE in the constant-potential mode differs to some extent from the measuring range of the corresponding potentiometric sensor, depending on the sign and the magnitude of the current signal (see also [7-9]).

Fig. 1 shows theoretical response curves calculated with Eqns. (9) and (10). At high activities, the linear dependence of the current on the logarithm of the sample activity is apparent. The lower detection limit (arrows) depends on the current (Eqn. (10)) and thus on the external potential. It increases with increasing negative current because cations are driven from the membrane into the sample. If the current is positive, the cation uptake by the membrane leads to an increased slope at low sample activities. This behavior is in full analogy to the potentiometric responses observed at zero-current when primary ion fluxes from the sample to the membrane come into play [34-36].

Fig. 2 shows preliminary results obtained from experiments on a $\mathrm{Ca}^{2+}$-selective membrane. The current responses were measured on the ISE cell at two different, relatively low, values of the applied potential E. The calculated curves obtained with otherwise identical parameters document that the response behavior of the present system follows the case described in Eqns. (7) and (9), respectively. Evidently, the two sets of data basically differ in the value of the total reference potential, $\mathrm{E}_{\mathrm{m}}^{\mathrm{o}}-\mathrm{E}$, which is decisive for the intercept of the current $v s$. $\log$ (activity) curve. The slope of the linear range is nearly the same for both curves and is consistent with a membrane resistance $\mathrm{R}_{\mathrm{ISE}}$ of around $2 \mathrm{M} \Omega$. The detection limits are slightly different, as predicted by Eqn. (10). Both detection limits are somewhat higher than for the usual case of potentiometric measurements since the observed currents at low sample activities are negative. The experimental results finally attest a good agreement with the theoretical ex- pectations. Details of extended studies on the present subject will be reported elsewhere [33].

\section{Conclusions}

At constant external potential, the current across ion-selective membranes is usually a linear function of the logarithm of the sample ion activity. This contrasts with the common behavior known from electrochemistry at the interface of two immiscible liquids where the current is directly related to the sample concentration. The results can be accounted for by a simple theoretical model.

\section{Acknowledgments}

The authors thank the Swiss National Science Foundation and the National Institutes of Health (grant R01-GM59716) for financial support.

Received: July 14, 2003

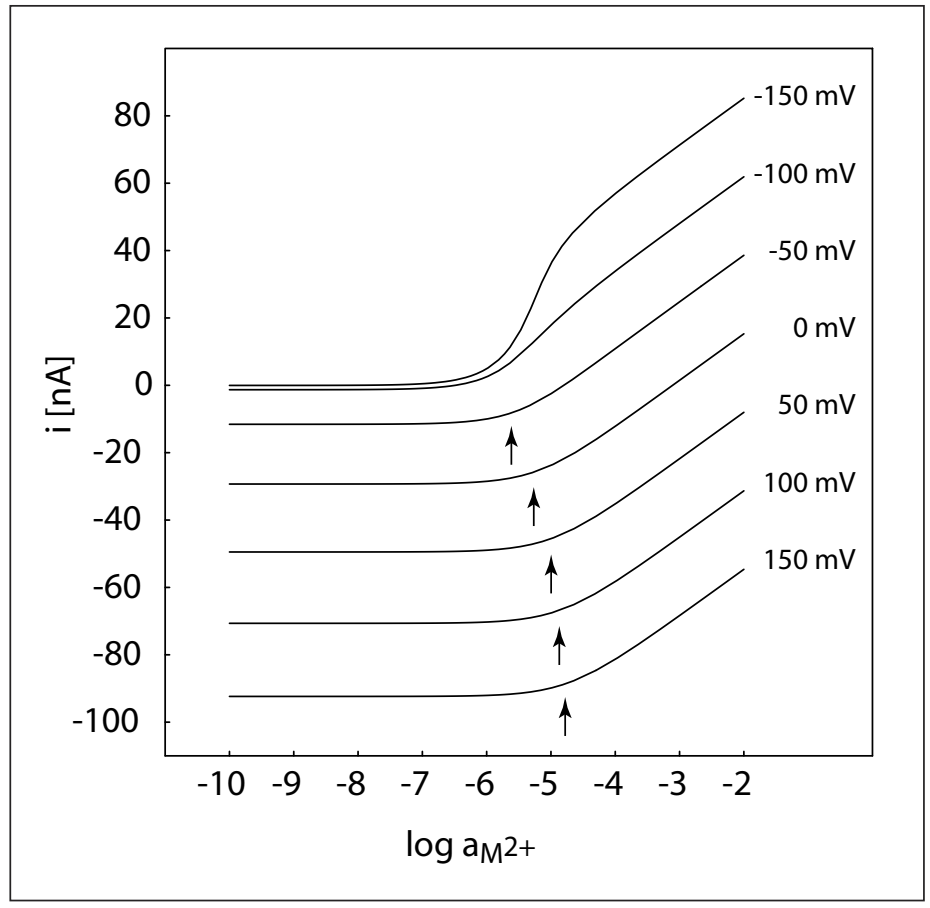

Fig. 1. Calculated response curves of a divalent ion-selective membrane at different external potentials E. Calculations according to Eqns. (9) and (10) using the following parameters: $\mathrm{R}_{\mathrm{ISE}}=2.145 \times 106 \Omega, \mathrm{E}_{\mathrm{m}}^{\mathrm{O}}=92 \mathrm{mV}, \mathrm{i}_{\mathrm{lim}} / \mathrm{a}_{\mathrm{m}}$ $=5 \mathrm{~mA} \mathrm{M}^{-1}$.

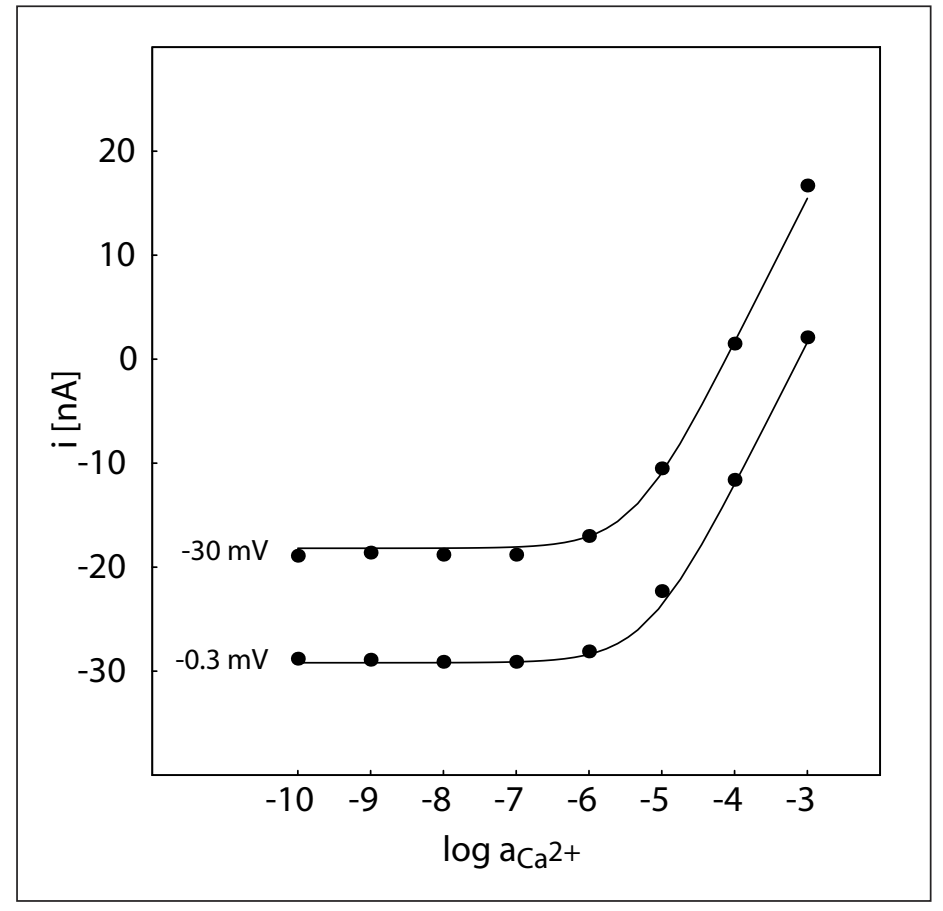

Fig. 2. Current response of a $\mathrm{Ca}^{2+}$-selective membrane (see Experimental) at two different external potential values. The superimposed calculated curves were obtained with the same parameters as in Fig. 1. 
[1] E. Bakker, M.E. Meyerhoff, Anal. Chim. Acta 2000, 416, 121.

[2] T. Sokalski, A. Ceresa, T. Zwickl, E. Pretsch, J. Am. Chem. Soc. 1997, 119, 11347.

[3] S. Mathison, E. Bakker, Anal. Chem. 1998, 70, 303.

[4] E. Bakker, E. Pretsch, Trends Anal. Chem. 2001, 20, 11.

[5] E. Bakker, E. Pretsch, Anal. Chem. 2002 74, 420A.

[6] A. Ceresa, A. Radu, S. Peper, E. Bakker, E. Pretsch, Anal. Chem. 2002, 74, 4027.

[7] E. Lindner, R.E. Gyurcsányi, R.P. Buck, Electroanalysis 1999, 11, 695.

[8] E. Pergel, R.E. Gyurcsányi, K. Tóth, E. Lindner, Anal. Chem. 2001, 73, 4249.

[9] W.E. Morf, M. Badertscher, T. Zwickl, N.F. de Rooij, E. Pretsch, J. Electroanal. Chem. 2002, 526, 19.

[10] T. Vigassy, W.E. Morf, M. Badertscher, A. Ceresa, N.F. de Rooij, E. Pretsch, Sens. Actuators B 2001, 76, 477.

[11] S. Peper, A. Ceresa, E. Bakker, E. Pretsch, Anal. Chem. 2001, 73, 3768.

[12] P. Reichmuth, P.D. van der Wal, M. Püntener, A. Schöning-Hammer, W.E. Morf, N.F. de Rooij, E. Pretsch, Anal. Chim. Acta 2002, 464, 79 .

[13] V. Marecek, Z. Samec, J. Koryta, Advances in Colloid and Interface Science 1988, 29, 1.

[14] P. Vanysek 'Electrochemistry on Liquid/Liquid Interfaces', Springer, Berlin, 1985.

[15] W.E. Morf, 'The Principles of Ion-Selective Electrodes and of Membrane Transport', Elsevier, New York, 1981.

[16] H.H.H. Girault, D.J. Schiffri, in 'Electroanalytical Chemistry', Ed.: A.J. Bard, Dekker, New York, 1989; Vol. 15, pp 1.

[17] V. Horvath, G. Horvai, Anal. Chem. Acta $1993,273,145$

[18] O. Shirai, S. Kihara, Y. Yoshida, M. Matsui, J. Electroanal. Chem. 1995, 389, 61.

[19] H.J. Lee, H.H. Girault, Anal. Chem. 1998 $70,4280$.

[20] H.J. Lee, P.D. Beattie, B.J. Murray, D. Osborne, H.H. Girault, J. Electroanal. Chem. 1997, 440, 73.

[21] S. Jadhav, E. Bakker, Anal. Chem. 1999, $71,3657$.

[22] S. Jadhav, E. Bakker, Anal. Chem. 2001 73, 80.

[23] B.D. Pendley, E. Lindner, Anal. Chem. 1999, 71, 3673 .

[24] B.D. Pendley, R.E. Gyurcsányi, R.P. Buck, E. Lindner, Anal. Chem. 2001, 73, 4599.

[25] J. Koryta, Electrochim. Acta 1984, 29, 445

[26] T. Kakiuchi, M. Senda, Bull. Chem. Soc. Jpn. 1984, 57, 1801

[27] C.R. Powley, R.F.J. Geiger, T.A. Nieman, Anal. Chem. 1980, 52, 705.

[28] E. Bakker, P. Bühlmann, E. Pretsch, Chem. Rev. 1997, 97, 3083.

[29] W.E. Morf, P. Wuhrmann, W. Simon, Anal. Chem. 1976, 48, 1031.

[30] A.P. Thoma, A. Viviani-Nauer, S. Arvanitis, W.E. Morf, W. Simon, Anal. Chem. 1977, 49, 1567
[31] W.E. Morf, L.F.J. Dürselen, W. Simon, in: Euroanalysis VI, Reviews on Analytical Chemistry, Ed. E. Roth. Les éditions de physique, Les Ulis Cedex; 271, Paris 1988.

[32] M.L. Iglehart, R.P. Buck, E. Pungor, Anal. Chem. 1988, 60, 290.

[33] J. Sutter, W.E. Morf, T. Zwickl, N.F. de Rodij, E. Pretsch, in preparation.

[34] T. Sokalski, T. Zwickl, E. Bakker, E. Pretsch, Anal. Chem. 1999, 71, 1204.

[35] T. Sokalski, A. Ceresa, M. Fibbioli, T. Zwickl, E. Bakker, E. Pretsch, Anal. Chem. 1999, 71, 1210.

[36] W.E. Morf, M. Badertscher, T. Zwickl, N.F. de Rooij, E. Pretsch, J. Phys. Chem. B 1999, 103, 11346. 